\title{
Effects of Silver Nanoparticles on Seed Germination and Seedling Growth of Radish (Raphanus Sativus L.)
}

\author{
Lifen Wang,2,a , Junzhen Zhu',b, Qiuyun \\ $\mathrm{Wu}^{1, \mathrm{c}}$,Yinghong Huang ${ }^{3, \mathrm{~d}}$ \\ ${ }^{1}$ Gold Mantis School of Architecture and Urban \\ Environment, Soochow University, Suzhou, 215123, China \\ ${ }^{2}$ Key Laboratory of Architecture and Urban Environment, \\ Suzhou, 215123, China
}

\begin{abstract}
The use of silver nanoparticles (AgNPs) in a wide range of consumer products has the furthered need to assess its impact on organisms. To date, there have been very few studies examining the effects of AgNPs on plants. This study investigated the impact of AgNPs to seed germination rate, seedling growth, peroxidase (POD) enzyme activity and chlorophyll content of a vegetable plant Raphanus sativus. Results showed that both AgNPs and $\mathrm{AgNO}_{3}$ had no significant effect on seed germination of $R$. sativus. Root length and root fresh weight was significantly reduced when exposed to $40 \mathrm{mg} / \mathrm{L} \mathrm{AgNPs}$ or $\mathrm{AgNO}_{3}$. It showed that the toxicity of AgNPs on $R$. sativus seedling growth is similar to $\mathrm{AgNO}_{3} .40$ $\mathrm{mg} / \mathrm{L}$ of AgNPs and $\mathrm{AgNO}_{3}$ significantly increase the activities of POD in $R$. sativus root and leaf. $R$. sativus bioassays employed in our experiments provided valuable information concerning the effects of AgNPs on plants.
\end{abstract}

Keywords-raphanus sativus; silver nanoparticles; seed growth; peroxidase; toxicity.

\section{INTRODUCTION}

Engineered nanoparticles (ENPs) are defined as intentionally produced particles that have a characteristic dimension between 1 and $100 \mathrm{~nm}$ in at least one dimension. ENPs possess novel properties that are not shared by non-nanoscale particles with the same chemical composition. Nanotechnology promises to far exceed the impact of the Industrial Revolution and is projected to become a $\$ 1$ trillion market by $2015^{[1]}$. Among these ENPs, silver nanoparticles (AgNPs) have a wide range of current and potential future applications, including chemical catalysts $^{[2]}$, spectrally selective coatings for solar energy absorption $^{[3]}$, surface-enhanced Raman scattering for imaging $^{[4]}$, and in particular, antimicrobial sterilization ${ }^{[5]}$. However, these effective and biocidal properties have the potential to adversely affect organisms in the environment. It is likely that measurable concentrations of AgNPs will find their way into the environment through product use and disposal, where they may exert adverse impacts on organisms ${ }^{[6]}$. Given their expected fate and potential toxicity, it is becoming widely recognized that the environmental impacts of nanomaterials need to be understood $^{[6,7]}$.

\author{
${ }^{3}$ Extension Center for Evergreen Fruit of Taihu, Suzhou \\ 215107, China \\ a email address: wanglfsuda.edu.cn@126.com, \\ bemail address: zhujz@suda.edu.cn, \\ cemailaddress:hyxhyh@126.com, demail address: \\ wanglf@sohu.com
}

However, our understanding of what AgNPs do to organisms or within natural environments is very limited, though the number of toxicological studies of AgNPs is rapidly increasing. Most studies to date have been conducted on bacteria, animal and human cells ${ }^{[8,9,10,11]}$ and algae $^{[12,13,14]}$. It is reported that that oxidative stress may play a significant role in the NPs toxicity in nitrifying bacteria $^{[9]}$ and human hepatoma cells ${ }^{[10]}$, but little is known about the influence in plants. To date, there is few report to study the possible activity changes of peroxidase (POD), one of antioxidant enzymes as reactive oxygen species (ROS) scavengers, in plants when they exposed to NPs.

There are few studies that investigate the impacts of AgNPs on plants. Stampoulis et al. (2009) reported that when $100 \mathrm{~nm}$ AgNPs at 500 and $100 \mathrm{mg} / \mathrm{L}$ resulted in 57\% and $41 \%$ decreases in plant biomass and transpiration, respectively, as compared to controls or to plants exposed to bulk $\mathrm{Ag}^{[14]}$. Kumari et al. (2009) investigate cytotoxic and genotoxic impacts of AgNPs on root tip cells of Allium cepa., the result showed that AgNPs could penetrate plant system and may impair stages of cell division causing chromatin bridge, stickiness, disturbed metaphase, multiple chromosomal breaks and cell disintegration ${ }^{[15]}$. The treatment of silver nanoparticles enhanced peroxidase and catalase activity of Bacopa monnieri (Linn.) Wettst ${ }^{[16]}$. These findings suggest that plants, as an important component of the ecosystems, need to be included when evaluating the overall toxicological impact of the nanoparticles in environment.

Radish (Raphanus sativus L.) is an economically important root vegetable crop produced throughout the world $^{[17]}$. It may be exposed to NPs via irrigation water contaminated with NPs and presents a threat to its growth. In this study, we sought to examine: (a) to ascertain the level of AgNPs required to inhibit the germination of $R$. sativus seeds, (b) to observe the growth of the seedlings under the treatment of AgNPs, (c) to evaluate the possible effect on the activity of POD of $R$. sativus induced by the AgNPs, and (d) compare the effect of AgNPs and $\mathrm{AgNO}_{3}$ on the seedlings. 


\section{MATERIALS AND METHODS}

\section{A. AgNPs and AgNO3 preparation}

AgNPs (AGS-WM2000) solution (2000mg/L) was obtained from Shanghai HuZheng Nano Technology Co., Ltd. Energy filtering transmission electron microscopy (TEM) was used to examine the particle shape and size of the AgNPs. $\mathrm{AgNO}_{3}$ was obtained from Shanghai Fine Chemistry Material Institute. All reagents, obtained from various commercial

sources,were of analytical or higher grades.

\section{B. Plant culture and treatment}

Seeds were immersed in a $75 \%$ alcohol solution for 1 min to ensure surface sterility. Then they were soaked in DI-water, nanoparticle suspensions or $\mathrm{AgNO}_{3}$ solution for about $2 \mathrm{~h}$ after been rinsed three times with DI-water. Three pieces of filter paper was put into each $120 \times 15 \mathrm{~mm}$ Petri dish, and $8 \mathrm{ml}$ of a test medium was added. Seeds were then transferred onto the filter papers, with 20 seeds per dish. Petri dishes were covered and sealed with tape, they were then placed in a growth chamber in random order where temperatures were $25 \pm 1{ }^{\circ} \mathrm{C}$ and $12 \mathrm{~h}$ light.1, 10 and 40 $\mathrm{mg} / \mathrm{L}$ AgNPs were prepared for testing the effect of AgNPs on the germination of $R$. sativus seed and seedling growth. Ag ions were used to compare the toxicities of AgNPs. The treatment with deionized (DI) water was comparison to compare the toxicities of AgNPs and Agions.

\section{Determination of biomass and POD activity}

At the end of the 4 days exposure, the root length was measured with calipers, the fresh weight was measured by analytical balance. POD activity was determined by the method of MacAdam (1992) and modification ${ }^{[18]}$. The reaction mixture contained $3 \mathrm{ml}$ reaction liquid $(100 \mathrm{mM}$ sodium phosphate buffer $(\mathrm{pH} 7.0), 28 \mu \mathrm{l}$ of 2methoxyphenol, $19 \mu \mathrm{l}$ of hydrogen peroxide (30\%) and 0.2 $\mathrm{ml}$ of enzyme extract or distilled water for control. The Chlorophyll content was measured by Chlorophyll Meter Model SPAD-502.

\section{Statistical analysis}

All errors are expressed as standard deviations (SD). Differences between treatments for the different measured variables were tested using one-way ANOVA (SPSS 13.0.1 for Windows), followed by Tukey HSD tests when differences significant at $\mathrm{p}<0.05$ were found.

\section{RESULTS AND DISCUSSION}

\section{A. Characterization of AgNPs}

AgNPs used for $R$. sativus toxicity studies were characterized by TEM (JEM-100CX II), which showed these nanoparticles were spherical in shape (Fig. 1). The average diameter of particle was $15 \mathrm{~nm}$. The $\mathrm{pH}$ value of AgNPs solution was $7.0 \pm 0.5$, The AgNPs density was 1.07 $\mathrm{g} / \mathrm{ml}$ (Table 1).
TABLE 1 CHARACTERISTICS OF SILVER ANOPARTICLES USED IN THIS STUDY

\begin{tabular}{ll}
\hline Index & Performance \\
\hline Appearance & Tawny \\
Concentration(Ag) & $\geq 5 \%$ \\
PH value & $7.0 \pm 0.5$ \\
Particle diameter & $15 \mathrm{~nm}$ \\
Conductivity & Passed \\
Density & $1.07 \mathrm{~g} / \mathrm{ml}$ \\
Purity & $99.99 \%$ \\
\hline
\end{tabular}

${ }^{\mathrm{a}}$ The data provided by producer.

B. Effects of AgNPs and AgNO3 on the growth of R. sativus seedlings

The germination rate of $R$. sativus ses ranged from $90 \%$ to $97 \%$, and there is no significant difference between control, $\mathrm{AgNO}_{3}$ and AgNPs treatment (Fig. 2). The results indicated that $\mathrm{AgNO}_{3}$, AgNPs do not have accurate toxic effect on $R$. sativus seed germination. This is consistent with the previous studies that nanoparticles had less effect on seed germination compare to seedling growth ${ }^{[19,20]}$. Seed coat plays a very important role in protecting the embryo from harmful external factors. Seed coats can have selective permeability[21]. Pollutants, though having obviously inhibitory effect on root growth, may not affect germination as they cannot pass through seed coats. This may explain the reason that seed germination was not obviously effected by AgNPs in this study.

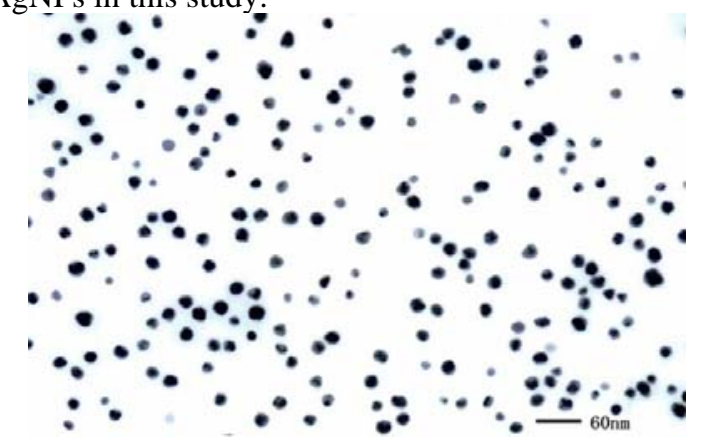

Figure 1. TEM images of $15 \mathrm{~nm}$ AgNPs. 


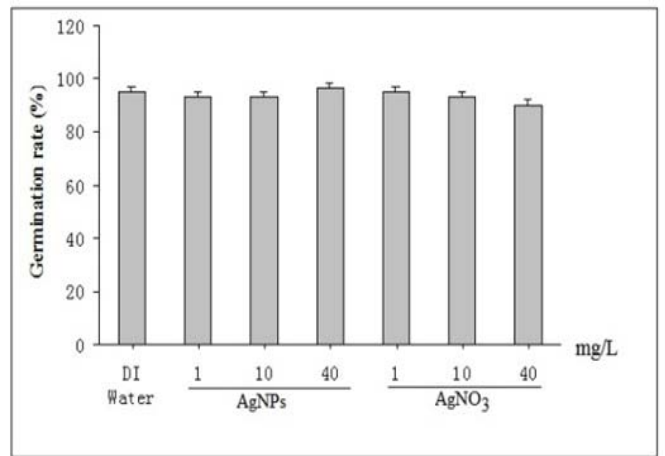

Figure 2. Effect of AgNPs and AgNO3 on the germination rate of $\mathrm{R}$. sativus seeds.

Both $\mathrm{AgNO}_{3}$ and AgNPs affected the growth of $R$. sativus seedlings, Three kinds of AgNPs solution (1, 10 and $40 \mathrm{mg} / \mathrm{L}$ ) had significant effect on root length, and significantly reduced root length (Fig.3). Similar effect was observed when $\mathrm{AgNO}_{3}$ was used. The fresh weight of root was also affected by both AgNPs and $\mathrm{AgNO}_{3}$. And there is significant difference between control and high concentration of AgNPs and $\mathrm{AgNO}_{3}$ treatment. When 40 $\mathrm{mg} / \mathrm{L}$ of AgNPs and $\mathrm{AgNO}_{3}$ was applied, the fresh weight reduced more than $45 \%$ percent (Fig. 4).Recent studies of AgNPs have frequently attributed their toxicity to the release of dissolved silver ${ }^{[12,13,5]}$, and thus ionic silver is much more toxic than AgNPs at the same concentration. Oukarroum et al (2013) reported that the significant decrease of frond numbers of the aquatic plant Lemna gibba was dependent on AgNPs concentration ${ }^{[22]}$. In this study, root length and root fresh weight was significantly reduced when exposed to $40 \mathrm{mg} / \mathrm{L} \mathrm{AgNPs}$ or $\mathrm{AgNO}_{3}$. It showed that the toxicity of AgNPs on $R$. sativus seedling growth is similar to $\mathrm{AgNO}_{3}$.

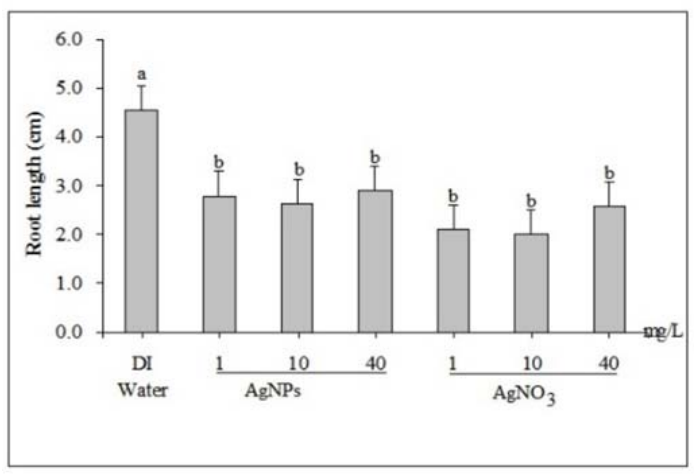

Figure 3. Effect of AgNPs and $\mathrm{AgNO}_{3}$ on the root length of R.sativus. Different letters show significant differences $(\mathrm{P}<0.05)$.

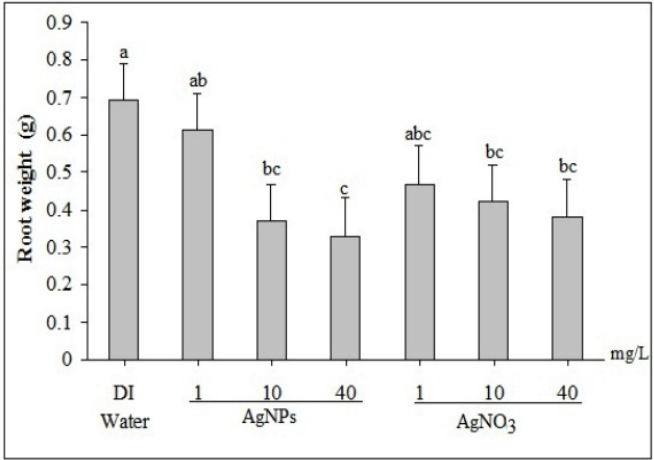

Figure 4. Effect of AgNPs and $\mathrm{AgNO}_{3}$ on the root weight of $R$. sativus. Different letters show significant differences $(\mathrm{P}<0.05)$.

\section{Effects of AgNPs and AgNO3 on the activity of POD}

POD activity, the protective enzyme for ROS stress, was measured, the results indicated that higher concentration of $\mathrm{AgNO}_{3}$ (10 and $40 \mathrm{mg} / \mathrm{L}$ ) significantly aroused the POD enzyme activity in roots, while lower dose of $\mathrm{AgNO}_{3}(1$ $\mathrm{mg} / \mathrm{L}$ ) had no significant effect when compared with the control (Fig. 5). AgNPs at $40 \mathrm{mg} / \mathrm{L}$ significantly enhanced the root POD activity, while $1 \mathrm{mg} / \mathrm{L}$ and $10 \mathrm{mg} / \mathrm{L}$ AgNPs had no significant effect when compared with the control. The POD activity in leaf indicated that both $\mathrm{AgNO}_{3}$ and AgNPs at $1 \mathrm{mg} / \mathrm{L}$ and $10 \mathrm{mg} / \mathrm{L}$ had no significant effect when compared with control. The POD activity in leaf significantly increased with treatments of $\mathrm{AgNO}_{3}$ and AgNPs at $40 \mathrm{mg} / \mathrm{L}$. (Fig. 6). It was shown previously that ROS are generated during plant metabolism, especially in the plants exposed to environmental stresses, and they need to be scavenged for maintenance of normal growth. Much evidence has accumulated from various plant systems showing that environmental stresses alter the activities of enzymes involved in scavenging $\operatorname{ROS}^{[23,24,25]}$. Among these enzymes, POD is one of the most important enzymes active in elimination of ROS. Previously studies showed that both dissolved silver and AgNPs can induce ROS production in bacteria and human hepatoma cells ${ }^{[9,10]}$. Peroxidase activity in the leaves of B. monnieri treated with AgNPs was significantly high and slightly higher than that of leaves treated with $\mathrm{AgNO}_{3}$ from 20thday of exposure ${ }^{[16]}$. In view of this, we investigated the activities of POD, one endogenous protective enzyme, to determine whether a general oxidative stress is also induced by AgNPs in plants. The results in this study demonstrated that high concentration of AgNPs and $\mathrm{AgNO}_{3}$ (40 mg/L) significantly increase the activities of POD in $R$. sativus root and leaf, which is consistent with the seedling biomass response. The findings suggest that POD may take part in the process in which plants react against the AgNPs stress. 


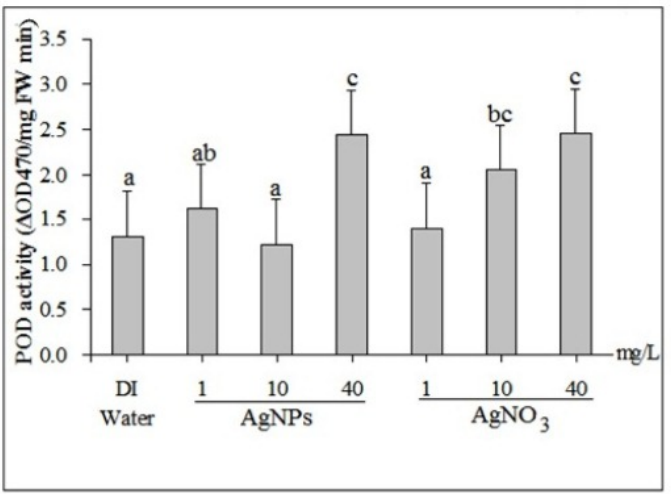

Figure 5. Effect of AgNPs and AgNO3 on the POD activity of R. sativus root. Different letters show significant differences $(\mathrm{P}<0.05)$.

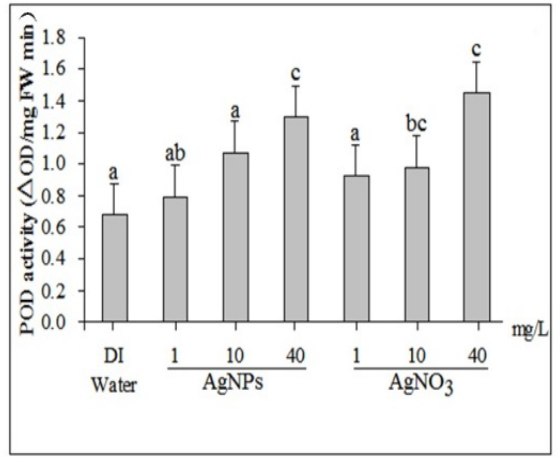

Figure 6. Effect of AgNPs and $\mathrm{AgNO}_{3}$ on the POD activity of $R$. sativus leaf. Different letters show significant differences $(\mathrm{P}<0.05)$.

\section{Effects of AgNPs and AgNO3 on the chlorophyll content of leaf}

Chlorophyll was the most important element in the photosynthesis. The chlorophyll contents of leaf reduced with the AgNPs and $\mathrm{AgNO}_{3}$ treatments. The higher concentration of $\mathrm{AgNO}_{3}$ (10 and $40 \mathrm{mg} / \mathrm{L}$ ) significantly reduced the chlorophyll content in leaves, while lower dose of $\mathrm{AgNO}_{3}(1 \mathrm{mg} / \mathrm{L})$ had no significant effect when compared with the control (Fig. 7). The chlorophyll content in leaves significantly decreased at AgNPs at $40 \mathrm{mg} / \mathrm{L}$.

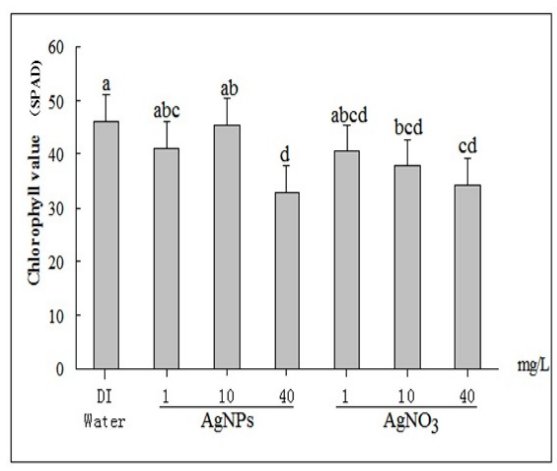

Figure 7. Effect of AgNPs and $\mathrm{AgNO}_{3}$ on the contents of chlorophyll of $R$. sativus leaf. Different letters show significant differences $(\mathrm{P}<0.05)$.

\section{CONCLUSIONS}

In this work, $R$. sativus bioassays employed in our experiments provided valuable information concerning the effects of AgNPs on plants. And our results indicate that exposure to AgNPs via irrigation water contaminated by AgNPs poses a threat to the yield and quality of vegetable plants in the environment. These results will help to further understand phytotoxicity of various nanomaterials, and are significant in terms of use and disposal of engineered nanoparticles. Future studies should be directed to phytotoxicity mechanisms of AgNPs, possible uptake and translocation of nanoparticles by plants and to examine whether the toxicity of AgNPs observed in this study also occurs in other plant species.

\section{ACKNOWLEDGMENT}

This work was supported by grants from the projectfund by Key Laboratory of Architecture and Urban Environment (AKLK13005).

\section{REFERENCES}

[1] A. Nel, T. Xia, L. Mädler and N. Li: Science. 311(2006), p. 622-627

[2] H.J. Zhai, D.W. Sun and H.S.Wang: J. Nanosci. Nanotechnol. 6(2006), p. $1968-1972$

[3] R.B.Rand, P. Peumans and S.R.Forrest: J. Appl. Physics. 96(2004), p.7519-7526

[4] S. Yamamoto and H. Watarai: Langmuir. 22(2006), p. 6562-6569

[5] S. Pal, Y.K.Tak and J.M.Song: Applied and Environ. Microbiol. (73) 2007, p.1712-1720

[6] C.O. Robichaud, D.Tanzil, U. Weilenmann and M.R. Wiesner: Environ.Sci. Technol. 39 (2005), p. 8985-8994

[7] M.R.Wiesner, G.V. Lowry, P.J. Alvarez, D. Dionysiou and P. Biswas: Environ.Sci. Technol.

40(2006), p. 4336-4345

[8] J.R. Morones, J.L.Elechiguerra, A.Camacho, K. Holt, J.B. Kouri, J.T. Ramirez and M.J. Yacaman: Nanotechnology. 16(2005), p. 23462353

[9] O. Choi and Z.Q.Hu: Environ. Sci. Technol. 42(2008), P.4583-4588

[10] S. Kim, J.E.Choi, J. Choi, K.H. Chung, K. Park, J. Yi and D.Y. Ryu: Toxicol. in Vitro. 23(2009), p.1076-1084

[12] A. Kahru and H.C. Dubourguier: Toxicology. 269 (2010), p.105-119 
[13] A.J. Miao, K.A. Schwehr, C. Xu, S.J. Zhang, Z.P. Luo, A. Quigg and P.H. Santschi: Environ. Pollut. 157 (2009), p. 3034-3041

[14] Dewez and A.Oukarroum: Toxicol. Environ. Chem. 94(2012), p.15361546

[15] D. Stampoulis, S.K. Sinha and J.C. White: Environ. Sci. Technol. 43 (2009), p. 9473-9479

[16] M. Kumari, A. Mukherjee and N. Chandrasekaran: Sci. Total Environ. 407 (2009), p. 5243-5246

[17] C. Krishnaraj, E.G. Jagan, R. Ramachandran, S.M. Abirami, N. Mohan and P.T. Kalaichelvan: Process Biochem. 47(2012): 651-658

[18] L.Z. Wang and Q.W.He: Chinese radish (Scientific and Technical Documentation Press, China 2005)
[19] J.W. MacAdam, R.E.Sharp and C.J. Nelson: Plant Physiol. 99(1992), p. 879-885

[20] D. Lin and B. Xing: Environ. Pollut. 150(2007), p. 243-250

[21] R.C. Monica and R. Cremonini: Caryologia. 62 (2009), p.161-165

[22] M. Wierzbicka and J. Obidzinska: Plant Sci.137(1998), p.155-171

[23] A. Oukarroum, L. Barhoumi, L. Pirastru and D. Dewed: Environ. Toxicol. Chem. 32(2013),p. 902-907

[24] Y.Gueta-Dahan, Z.Yaniv, B.A. Zilinskas and G. Ben-Hayyim: Environ. Pollut. 159(1997), p. 1551-1559

[25] L.Y.Yin, J.Q.Huang, W.M. Huang, D.H. Li, G.H. Wang and Y.D. Liu: Toxicon. 46(2005), p. 507-512

[26] J.Q. Huang, H.F. Jiang, Y.Q. Zhou, Y. Lei, S.Y. Wang and B.S. Liao: Int. J. Food Microbiol. 130 (2009), p.17-21 